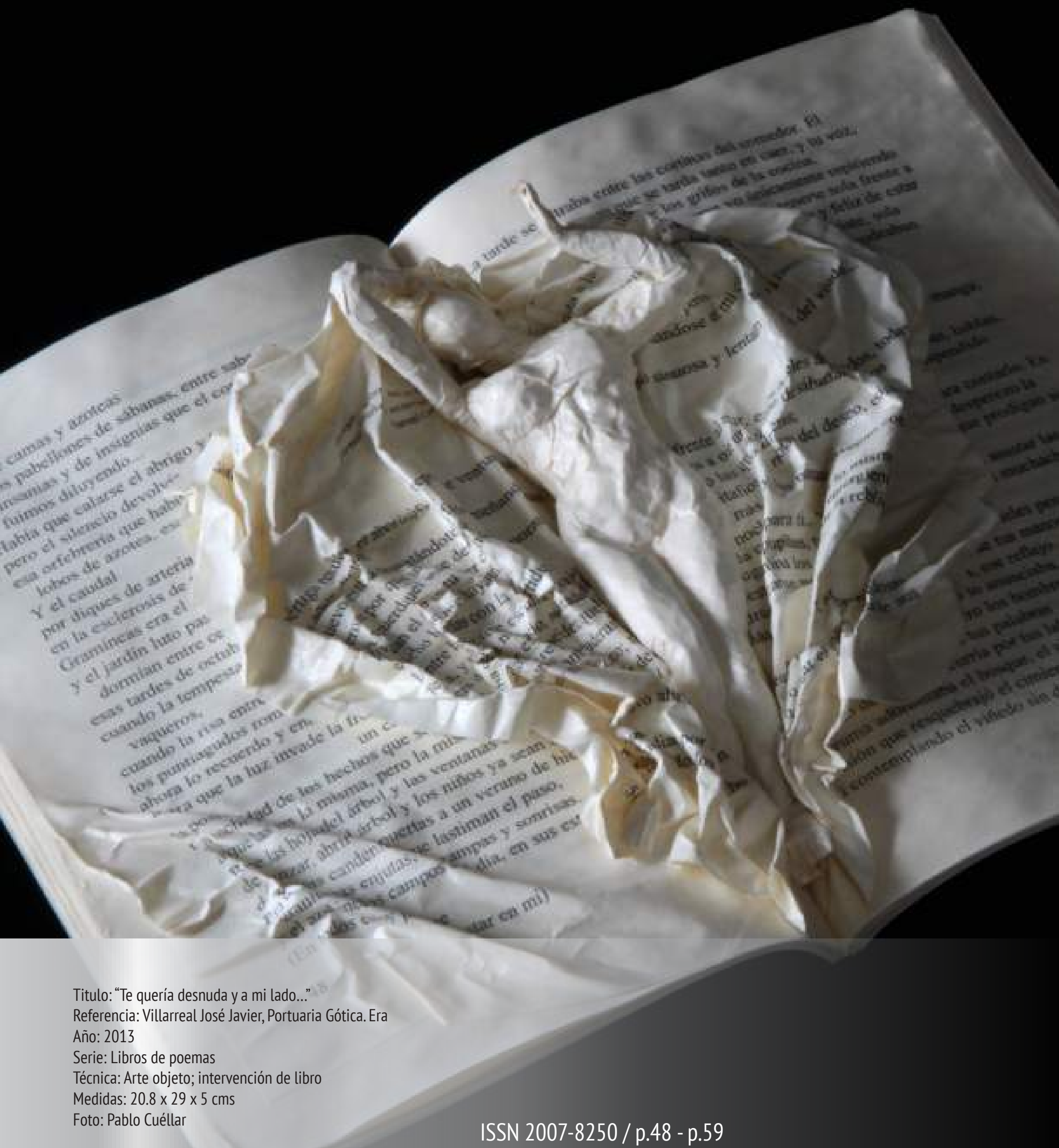




\title{
La historia no contada de las mujeres en la ciencia
}

\author{
The untold story of women in science
}

\section{Artemisa Flores Espínola}

\section{Resumen}

El programa de investigación sobre mujeres en la ciencia surge a finales de los años setenta con el objetivo de explicar la escasez de mujeres. Los trabajos en historia fueron los más importantes para visibilizar aquellas científicas que fueron con el tiempo olvidadas o que su trabajo fue considerado como doméstico en vez de científico. Con el tiempo los estudios se multiplicaron hasta constituir un corpus significativo en diversas disciplinas, que permitió identificar las principales barreras estructurales en las trayectorias de las científicas. Este artículo busca, en primer lugar, mostrar el aporte de los estudios de género para desvelar el sexismo y las lógicas de poder y dominación en la ciencia. En segundo lugar, a través del método de los estudios de caso, el texto demuestra que incluso dos de las científicas más importantes en la historia de la ciencia experimentan el 'efecto Matilda' de las mujeres en ciencia.

Palabras clave: academia, sexismo, género, historia, ciencia, tecnología.

\begin{abstract}
The research program on women in science emerged at the end of the 1970s with the aim of explaining the scarcity of women. The works in history were the most important to make visible those scientific ones that were forgotten with time or that their work was considered domestic instead of scientific. Over time the studies multiplied to form a significant corpus in various disciplines, which allowed identifying the main structural barriers in the trajectories of women scientists. This article seeks, in the first place, to show the contribution of gender studies to reveal sexism and the logics of power and domination in science. Secondly, through the method of case studies, the text shows that even two of the most important scientists in the history of science experience the 'Matilda effect' of women in science.
\end{abstract}

Keywords: scholarship, sexism, gender, history, science, technology. 
$\mathrm{D}$ esde los orígenes del movimiento feminista, las mujeres utilizaron las herramientas teóricas y políticas a su alcance para exigir la igualdad en el ámbito académico.

El movimiento feminista inicia en el siglo XVIII con la Ilustración, que hace surgir la bandera de la razón y permite así reivindicar la igualdad entre los sexos frente a los principios biologicistas, tradicionalistas y de culto al pasado que daban fuerza a la idea ya bien consolidada de la inferioridad y supeditación de las mujeres a los hombres (Amorós, 1997).

Siguiendo a Maguire, en este artículo el feminismo es entendido de la forma siguiente:

(a) creencia de que las mujeres universalmente se enfrentan a formas de opresión y explotación; (b) un compromiso para desvelar y comprender lo que causa y sustenta esta opresión, en todas sus formas y (c) un compromiso de trabajar individualmente y colectivamente en la vida diaria para finalizar todas las formas de opresión (Maguire, 1987: 79).

El feminismo como movimiento social y político surge de las filas de una corriente de pensamiento que, aunque incipiente, marcará radicalmente una diferencia en el modo de ver la vida y la sociedad en la época moderna: la llustración. Sin embargo, aunque por un lado, la llustración ofrecía alternativas ideológicas de igualdad, por el otro limitaba esa igualdad al mundo de los varones y sometía la naturaleza a la más absoluta dominación por la técnica y la ciencia positivistas (Molina Petit,
1994). El feminismo se va gestando a partir de un proceso de reflexión en torno a la resignificación de la idea ilustrada de igualdad.

Este telón de fondo ilustrado y revolucionario del siglo XVIII proporcionó a las mujeres referentes para una vindicación de derechos, como son la educación, el derecho al trabajo, 0 el derecho al voto. Beltrán Pedreira (2001) señala que los caminos que siguió el movimiento feminista europeo fueron diferentes de los del continente americano.

Mientras que las reivindicaciones de las francesas no tuvieron un reconocimiento por parte de la mayoría de las mujeres, en Estados Unidos consiguieron establecer fructíferas alianzas con mujeres de clase media que les llevarían al éxito político (Beltrán Pedreira, 2001: 36).

En el siglo XIX, un grupo de mujeres en Estados Unidos y después en Inglaterra y Francia, se movilizaron en torno al sufragio. Este movimiento social internacional se le denomina el 'sufragismo' y es considerado por las anglosajonas como la primera ola del feminismo. Otras muchas autoras, como por ejemplo Beltrán Pedreira y Amelia Valcárcel (2000), proponen considerar como primera ola la vindicación ilustrada, bastante ignorada por las feministas anglosajonas. El sufragismo tiene sus raíces en el movimiento abolicionista estadounidense y sus principales figuras fueron Elizabeth Cady Stanton y Susan Anthony.

Habrían de pasar muchos años más para que las feministas volvieran a conformar un grupo importante de

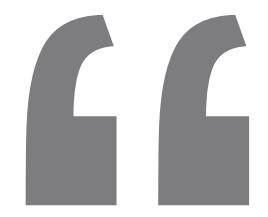

Beltrán Pedreira y Amelia Valcárcel (2000), proponen considerar como primera ola la vindicación ilustrada, bastante ignorada por las feministas anglosajonas". 
mujeres que lucharan desde diferentes espacios - la academia, la población civil, entre otras- hasta organizar un gran movimiento social que tiene lugar a finales de los años setenta. Este movimiento social surge debido a unas condiciones históricas y materiales específicas, como fueron las grandes movilizaciones sociales de mayo de 1968 francés, el 2 octubre de 1968 en México, así como una serie de luchas en otras partes del mundo.

Teniendo como consecuencia múltiples reflexiones en las universidades y en los lugares de investigación sobre las cuestiones y debates entre el activismo político y la academia, un tema recurrente después del proceso de institucionalización del feminismo a través de lo que se conoce como los departamentos de estudios sobre las mujeres.

El feminismo académico apareció fundamentalmente en las humanidades y ciencias sociales con el fin de examinar lo que se ha dicho de las mujeres, documentar sus contribuciones en diferentes campos y explicar los mecanismos que mantienen su subordinación y marginalización.

Los primeros programas de investigación sobre mujeres en la ciencia fueron desarrollados para explicar por qué había tan pocas mujeres en ciencias. Los trabajos en historia fueron los más importantes para visibilizar la obra de científicas que habían pasado al olvido o que su trabajo fue considerado como doméstico en vez de científico (obstetricia, astronomía, etcétera). Los trabajos en estas áreas se multiplicaron hasta formar una vasta literatura que permitió identi- ficar las principales barreras estructurales a las que se enfrentan las mujeres.

Este artículo tiene como primer objetivo mostrar el aporte de los estudios de género para desvelar el sexismo y las lógicas de poder y dominación en la ciencia. El segundo objetivo, es demostrar que incluso dos de las científicas más importantes en la historia de la ciencia experimentan el 'efecto Matilda' de las mujeres en ciencia.

Para realizarlo se utiliza el método del estudio de casos para ejemplificar esa otra historia de dos científicas en ciencias naturales. El caso de Marie Curie y Rosalind Franklind, ejemplifican que si ellas se toparon con obstáculos y barreras en su trayectoria, imaginemos la situación de la gran mayoría de científicas. La suma de pequeñas discriminaciones provoca la exclusión los puestos de poder en ciencia, lugares donde se deciden, por ejemplo, los programas de investigación que serán financiados, las personas que tendrán una plaza o el reconocimiento de la comunidad científica.

Marco teórico: la interacción entre género y ciencia

Una herramienta teórica clave en el desarrollo del feminismo académico fue la creación de la teoría feminista de género (El género ha sido considerado como una variable, un concepto o una categoría, sin embargo, los estudios de género en la academia han conformado unos contenidos y prácticas específicas que permiten considerarla como una teoría crítica originada en la reflexión feminista). Este término ha tenido problemas para ser entendido en la academia,

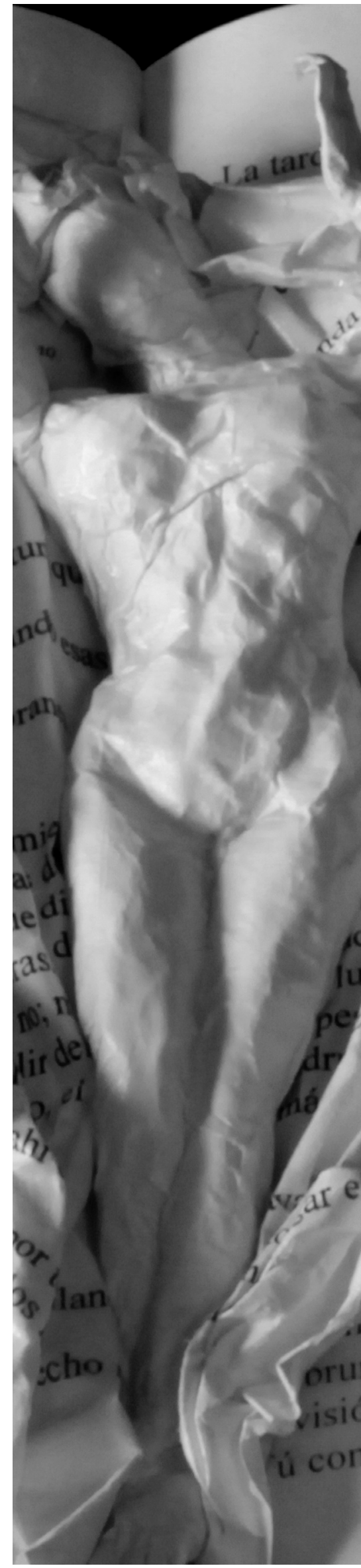

Presencia Universitaria 


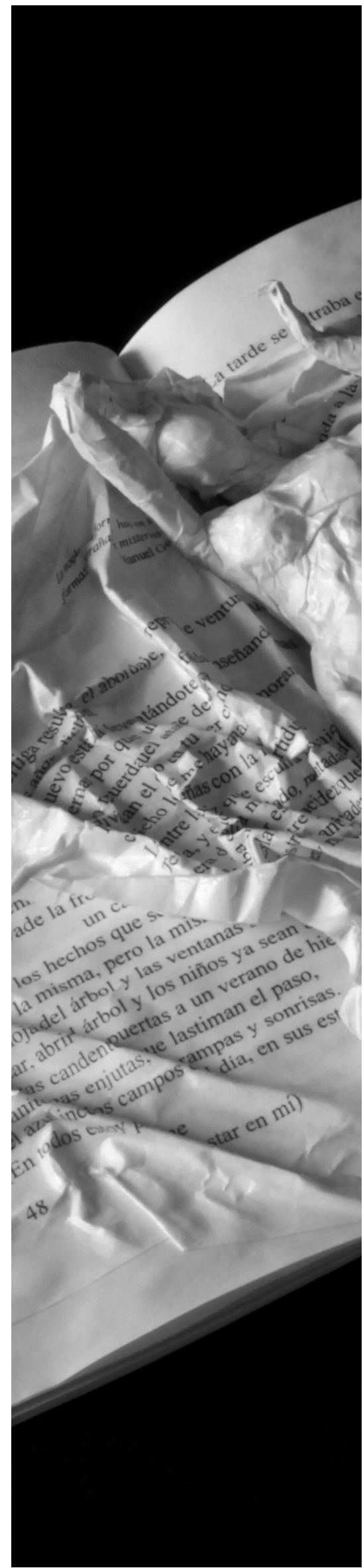

por ser un concepto abstracto tomado del inglés. El género, como se le conoce en los ámbitos académicos, ha sido una poderosa herramienta para combatir evidencias y facilitar la desnaturalización de la diferencia sexual. A partir de la década de los setenta su uso comienza a difundirse en muchos países y sus aportes han sido incontestables.

Cuando se habla de género, se busca distinguir la noción de 'sexo' biológico, -hormonas, genes-, de la del 'género' social. Desde siempre, incluso en la investigación científica, como veremos más adelante, se explican las diferencias sexuales entre los hombres y las mujeres por la biología. Es decir, el hecho de tener órganos sexuales diferentes determinaría a las mujeres a comportarse socialmente de una manera y a los hombres de otra.

A pesar de ser una idea bastante difundida, basta con analizar los casos de niños y niñas intersexo -que nacen con un sexo indefinido- para darnos cuenta del peso de lo social en nuestro desarrollo del ser humano. La teoría feminista del género explica que la diferencia de comportamientos entre los sexos no tiene una base biológica, sino cultural y social. Este mismo argumento de naturalización ha sido y es utilizado para justificar el 'racismo' y las clases sociales en nuestra sociedad.

Con la 'teoría feminista del género', el feminismo pasó a convertirse, además de un movimiento político, en una teoría crítica. El género permite el cuestionamiento y reformulación de teorías y asunciones deterministas sobre el comportamiento humano, que explican el inferior estatuto social de las mujeres por una supuesta diferencia biológica entre los sexos (Ortner, 1979; Rosaldo, 1974). La teoría de género ofrece una base firme para combatir en el plano teórico y luchar desde el plano político por un cambio social (Rubin, 1986; Lamas, 1994; Lagarde, 1997).

Como se ha dicho antes, los estudios de género surgen en un contexto específico de movilización social a mediados de los años setenta, junto con otras movilizaciones sociales importantes como el movimiento ecologista o pacifista, que plantean su escepticismo ante el futuro de la sociedad. Estas preocupaciones dan lugar a los estudios de ciencia, tecnología y sociedad (CTS). Los estudios CTS buscan entender aquellos aspectos sociales del cambio científico-tecnológico, particularmente los condicionantes y las consecuencias sociales y ambientales.

Por su parte, los estudios de ciencia, tecnología y género (CTG) buscan integrar el género como teoría crítica relevante para comprender los efectos de la ciencia y la tecnología sobre nuestros modos de vida y los procesos de su producción. Los estudios CTG se consolidan con la publicación de los libros: Alice trough the microscopy (1980) que escribe el grupo Brighton de Mujeres y Ciencia; el libro de Janet Sayers Biological Politics: feminist and anti-feminist perspectives (1982) y finalmente el libro de Evelyn Fox Keller $A$ feeling for the organism (1983). Otros libros que continuaron con sus aportaciones desde el feminismo y que siguen siendo muy influyentes son: Science and gender: a critique of Biology and 
its theories on women de Ruth Bleier (1984) y unos años después Reflections on gender and science de Evelyn Fox Keller (1983/1984) y sobre todo The science question in feminism de Sandra Harding (1986/1996).

Los estudios CTG han producido no sólo una reflexión intensa en cuanto a la participación de las mujeres $y$ los hombres en la ciencia y en la tecnología, sino también una profunda crítica de la práctica científica y tecnológica. Durante varias décadas los análisis feministas han explorado el estatus y las barreras que han limitado las oportunidades de las mujeres en la ciencia y la tecnología y desde diferentes disciplinas han creado un número significativo de contribuciones. Los primeros trabajos comenzaron con la constatación de la escasez de mujeres en la práctica y en el proceso científico y tecnológico, dando como resultado estudios que buscaban recuperar del olvido a mujeres científicas y tradiciones realizadas por mujeres.

Se desvelaron las barreras explícitas que impedían el acceso de las mu- jeres al conocimiento. No obstante, los estudios en curso sustentan que existen también barreras implícitas que impiden el acceso en igualdad de condiciones para hombres y mujeres. Pero sobre todo, se han puesto de manifiesto los mecanismos ideológicos que han ayudado a mantener esta situación de desventaja para las mujeres en la tecnociencia.

Sexismo en la historia de la ciencia: el caso de Marie Curie y Rosalind Franklind

En el seno del feminismo existen algunas historiadoras de la ciencia que han cuestionado algunos de los trabajos realizados durante estos años para rescatar las aportaciones científicas de las mujeres a la ciencia, como las biografías que se realizaron sobre Marie Slodovska Curie o Rosalind Franklind. Schiebinger (1987) critica que estos trabajos hayan hecho lo mismo que el modelo masculino de describir los méritos de gente renombrada. En cambio, sugiere que la obra de Margaret Rossiter (1982) o Evelyn Fox Keller (1983/1984) aportan una historia muy diferente al analizar la estructura de la ciencia.
Rossiter mostró que las mujeres habían estado presentes en el quehacer científico, pero participando desde diferentes lugares, por ejemplo, se encargaban de realizar observaciones, compilar datos y muestras, lo cual forma una parte fundamental de la investigación, pero esto no fue tomado en cuenta, fue silenciado, este trabajo enmarcado como trabajo doméstico, no fue considerado como científico.

Keller, por su parte, señala que el mundo científico tardó décadas en darse cuenta de la valiosa contribución de Bárbara McClintock por tener un estilo diferente de hacer ciencia, pero que finalmente galardonada con el prestigioso premio Nobel.

Los trabajos de Rossiter y Keller permitieron reescribir la historia de las mujeres en la ciencia, es decir, contribuyeron para que la historia sea cada más completa. Una gran parte de los estudios realizados permitieron también poner en evidencia que la situación de las mujeres que habían logrado destacar en el mundo científico era excepcional y privile-

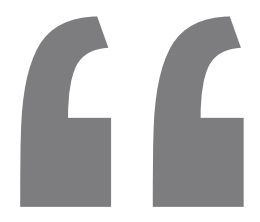

\section{Rossiter mostró que las mujeres habían estado presentes en el quehacer científico, pero participando desde diferentes lugares".}


giada. Estas mujeres científicas sobresalieron porque tuvieron condiciones que lo favorecieron, como por ejemplo, eran hijas de científicos 0 estaban casadas con alguno y provenían de clases adineradas. Si bien estas situaciones específicas no las tuvieron muchas mujeres, su participación fue mucho más importante de lo que imaginamos.

Analizar la historia de las mujeres desde una perspectiva diferente fue posible gracias a herramientas y conceptos nuevos, como lo es el marco

Estas mujeres científicas

\section{sobresalieron}

porque tuvieron

condiciones que lo favorecieron, como por ejemplo, eran hijas de científicos o estaban casadas con alguno y provenían de clases adineradas". conceptual proporcionado por la teoría de género feminista.

Gracias a los trabajos de recuperación de la historia de las mujeres que han tenido lugar en los últimos años, en su mayor parte realizados por académicas feministas, se sabe que existieron muchas mujeres que pudieron entrar a ese reducido número de personas que desarrollan la ciencia y la tecnología (Alic, 1991; Rossiter, 1982; Schiebinger, 1999).

Ha sido un trabajo arduo y sin duda imprescindible el realizado por las historiadoras para recuperar las figuras femeninas que hicieron grandes aportaciones a la ciencia y a la tecnología y que siguen siendo desconocidas para la gran mayoría de la población. En gran medida esto se debe a un sesgo de género en la historiografía. La historia es siempre contada por los que tienen poder y en esta sociedad patriarcal son los hombres - blancos, burgueses, occidentales, heterosexuales - los que han escrito la historia de la humanidad. En el caso particular de la ciencia y la tecnología, las mujeres en esta historia no aparecen representadas por los historiadores, y si lo hacen, es por ser esposas, madres, hermanas 0 amigas de algún varón.

Aunque actualmente existe una gran cantidad de estudios dedicados a buscar la vida y obra de mujeres presentes en la historia de la ciencia, la realidad es que los libros recientes siguen sin mostrar las contribuciones de las mujeres a la historia de la ciencia. El caso ejemplar en la historia de la ciencia lo constituye Marie Curie, quien quizás ha sido la mujer que ha logrado tener el mayor reconocimiento como científica. Sin embargo, su figura es tan excepcional para la ciencia, que hay quienes opinan que exaltar mucho su obra es contraproducente, ya que obscurece la obra de otras muchas mujeres científicas y puede también desalentar a otras científicas que ven su obra como algo fuera de su alcance (Almodovar, 1996).

Su obra ha sido digna de muchas biografías, libros y películas, pero se ha prestado poca atención a los obstáculos experimentados por Marie Curie en su trayectoria científica. Su caso puede darnos el mejor ejemplo de cómo a una científica, a la que la comunidad científica reconoció con el máximo galardón en ciencias, el premio Nobel, le fue negado, al mismo tiempo, el acceso a la prestigiosa Academia de Ciencias Francesa. $Y$ esto sucedió poco tiempo antes de que recibiera su segundo premio Nobel - mérito que ningún hombre 0 mujer había obtenido en toda la historia de la ciencia-.

Podríamos cuestionar si Marie Curie hubiera logrado ser tan famosa si su esposo Pierre hubiera seguido vivo, 
ya que habitualmente cuando las mujeres participan con sus maridos, sus trabajos se vuelven invisibles y los méritos son reconocidos sólo para el científico y no para su esposa. Creo que éste hubiera podido ser también el caso de Marie Curie, y para argumentarlo, voy a criticar el argumento de Helena Pycior (1993), quién atribuye la fama de Marie Curie al establecimiento de una reputación científica.

Su trabajo sostiene que a pesar de las dificultades a las que se enfrentó Marie Curie, el factor clave fue la política de publicación entre ambos esposos, ya que cada uno reclamaba crédito por sus contribuciones individuales, así como por las conjuntas. Menciona que, en 1902, Marie Curie ya había publicado resultados clave tanto en Física como en Química, lo que le permitió una temprana prominencia en la comunidad científica francesa, destacando que sus trabajos individuales los firmaba como Marie Slodowska Curie.

El caso de Marie Curie me servirá para demostrar que a pesar de su importante notoriedad, tuvo que enfrentarse a las discriminaciones de sus colegas y de las instituciones científicas en general. El primer ejemplo de esta situación fue durante la selección de ambos para el premio Nobel de Física en 1903. Pycior señala que Marie no había sido considerada en la premiación y que mientras el comité deliberaba, la matemática sueca Gösta Mittag-Leffler contactó a Pierre para decirle que estaban intentando excluir a Marie del premio. Pierre Curie escribe entonces al comité para decirles que si habían pensado en él para el premio, desearía ser considerado junto con Marie Curie. Finalmente el comité de Física toma en cuenta su demanda y les otorga el premio compartido (cf. Pycior, 1993: pp. 312-313).

Incluso para científicas de la talla de Marie Curie, existieron obstáculos importantes debido a que era una mujer. Antes de morir Pierre Curie, ya empezaban a considerar los trabajos de ambos como realizados únicamente por él. Otro ejemplo ocurre cuando Pierre Curie obtiene el premio La Caze que otorga la Academia Francesa, y que constituye el más prestigioso reconocimiento, el cual se lo dieron al considerar sus importantes contribuciones a la ciencia, sin importar que, con muy pocas excepciones, éstas contribuciones fueron realizadas de forma conjunta con Marie Curie.

En cambio para reconocer la labor de Marie Curie, la Academia de Ciencias Francesa le otorgó el premio Gagner tres veces, un premio de menor prestigio y menor compensación económica. Pycior señala que a la muerte de Pierre Curie el obituario de la revista Nature lo define como un científico que hizo importantes contribuciones a la ciencia y mencionan sus tres más importantes: un nuevo elemento que induce radioactividad, la carga negativa de los rayos beta y la evolución espontánea de calor desde el radio, sin decir que las dos primeras fueron descubrimientos conjuntos de los Curie.

La vida de esta pareja científica muestra cómo Pierre Curie va teniendo cada vez mayor reconocimiento, que culmina con la entrada de Pierre Curie a la Academia de Ciencias en

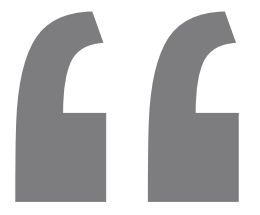

Durante varias décadas los análisis feministas han explorado el estatus y las barreras que han limitado las oportunidades de las mujeres en la ciencia y la tecnología". 


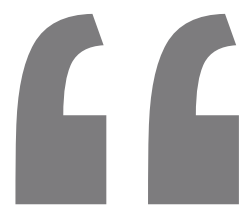

\section{Esta peculiaridad} sobre los trabajos

realizados por

científicos de

renombre de

atribuirles como

individuales

trabajos realizados

en conjunto, o que

tal vez ni siquiera

realizaron, es un

fenómeno que el

sociólogo Robert

Merton denominó

como efecto

Mateo".

-- Merton, 1968
1905 - privilegio que le fue negado a Marie Curie-. Esta peculiaridad sobre los trabajos realizados por cientíicos de renombre de atribuirles como individuales trabajos realizados en conjunto, o que tal vez ni siquiera realizaron, es un fenómeno que el sociólogo Robert Merton denominó como 'efecto Mateo' (Merton, 1968).

Haciendo referencia al 'efecto Mateo' descrito por Merton, Margaret Rossiter elabora a su vez el 'efecto Matilda', para explicar este fenómeno vivido por las mujeres en la ciencia y la tecnología (1993). Ella cuestiona que cuando Merton denuncia lo que denomina el "efecto Mateo", no prestó atención a toda la sentencia bíblica de Mateo - de donde toma el nombre-, porque sí bien, en su primera parte menciona que, aquellas personas que tienen, se les dará más y tendrán más abundancia; continua diciendo que, aquellas personas que no tienen, de ellos tomarán incluso las personas que tienen.

Es precisamente esta segunda sentencia, lo que la autora define como el "efecto Matilda". A pesar de las diversas discriminaciones experimentadas por Marie Curie, para Rossiter, ella podría considerarse como una excepción, debido a la consolidación de su fama y la obtención de los mayores reconocimientos de la comunidad científica. Su importancia es tan grande, que pocos hombres pueden llegar a tener tal reconocimiento.

En cambio, utiliza el caso de otras científicas para ejemplificar el "efecto Matilda", entre ellos el de Rosalind Franklind. Su caso es bastante triste, ya que ella nunca tuvo el reconocimiento de la comunidad científica por sus hallazgos. Franklind encontró la estructura que se denomina la doble hélice en la estructura del DNA $y$ sin este elemento no hubiera sido posible descifrar el código genético.

Su historia fue conocida por el libro de James Watson (2000), donde señala que fue Rosalind la que descubrió la estructura con la forma de doble hélice. Lo que sabemos, gracias a estas informaciones, es que hubo dos eventos que fueron cruciales para que Watson y Crick pudieran tener la información necesaria para poder encontrar la estructura del DNA y que Franklind nunca supo:

One was that Wilkins showed Watson Franklin's best $X$-ray diffraction image; wich clearly indicated that DNA forms a helix. The other was that Max Perutz, a senior researcher at Cambridge, received a research report the King's group has submitted to their funders. Knowing of Watson's and Crick's interest in DNA, he showed them the report, which included the conclusions Franklind had drawn on the basis of her $\mathrm{X}$-ray image, conclusions that specified all the critical dimensions of the DNA helix (Hubbard, 2003: 797).

De esta forma, Watson y Crick obtuvieron la información de manera poco honesta. El hallazgo de la estructura en forma de doble hélice fue la clave central para descubrir la estructura del ADN y que los hizo acreedores del premio Nobel. En cambio Franklind nunca fue reconocida por su trabajo. Estos dos afamados cientíicos se expresan en términos peyorativos sobre ella, seguramente debido a su temprana muerte. 


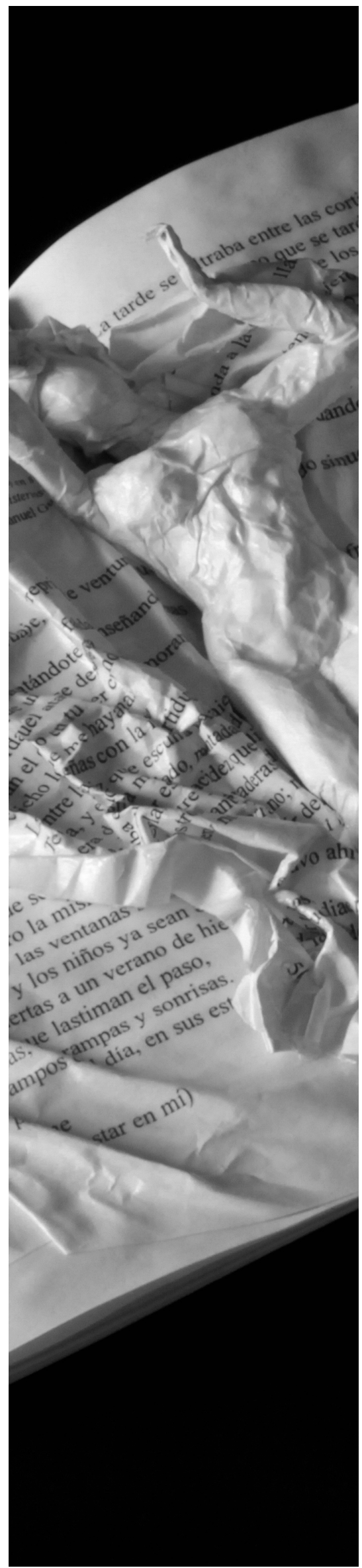

Ambos reconocen cómo utilizaron sus investigaciones sin que ella lo supiera y, a pesar de este hecho, ninguno le dio crédito por el trabajo tan importante que realizó.

Es necesario tener en cuenta las formas de discriminación definidas anteriormente para poder rehacer la historia de las mujeres en la ciencia. Seguir insistiendo por el pleno reconocimiento de científicas y tecnólogas que hoy siguen ausentes y desconocidas para la gran mayoría, fuera del ámbito del feminismo.

Los obstáculos de las mujeres en la academia se vuelven cada vez menos explícitos, pero no por ellos menos eficaces. Durante los primeros siglos las mujeres practican la ciencia y la tecnología, pero si en la antigüedad había sido difícil para las mujeres acceder al conocimiento, el origen de lo que se conoce como ciencia moderna está marcado por barreras que excluyen a las mujeres científicas.

La creación de las universidades y de las Academias de Ciencia en Europa permite su exclusión, ya que se les niega el ingreso. Al impedirles el acceso al conocimiento, la ciencia y la tecnología se establecen como prácticas masculinas (Schiebinger, 1989/2004; Pérez Sedeño, 1999; Frías Ruiz, 2001).

Los aportes de los estudios de género al campo de la ciencia y la tecnología han sido significativos, no sólo participando en la reconstitución de una historia más completa del mundo, pero también en la creación de nuevos conceptos que permitan explicar las diferencias sociales entre los sexos, sin perder de vista los efectos de la intersección entre el género, la 'raza' y la clase. El sistema educativo y el mundo académico, en general, reproduce las desigualdades sociales en vez de combatirlas (Bourdieu, 2012). El capital económico, escolar, cultural o militante permite a muy poca gente apropiarse los códigos necesarios para lograr el éxito académico. Una gran mayoría deserta la escuela antes de entrar a la universidad y serán entonces las mismas personas las que llegan y se encargan a su vez de enseñar a las futuras generaciones.

Este artículo pone de manifiesto la importancia de la teoría feminista del género para analizar los obstáculos a los que se enfrentan las mujeres en su trayectoria científica y en particular sobre los efectos para la ciencia misma de que la ciencia sea realizada en su mayoría por hombres blancos, heterosexuales, de clase media. La participación de las mujeres en la ciencia ha ido cambiando las prácticas científicas, aportando puntos de vista diferentes, añadiendo nuevas cuestiones y temas de investigación o utilizando nuevos métodos de investigación. ¿Cómo sería una ciencia y tecnología donde otros puntos de vista fueran representados? 


\section{Referencias}

Alic, Margaret (1991). El legado de Hipatia. Historia de Mujeres desde la Antigüedad hasta finales del siglo XIX. Ed. SigloXXI, Madrid;

Almodóvar, Miguel A. (1996). Mujer y ciencia en Iberoamérica. Invisibilidad y familia. En: Teresa Ortiz Gómez, Gloria Becerra Conde (eds.). Mujeres de ciencias. Mujer, feminismo y ciencias naturales, experimentales y tecnológicas. (Teresa Ortiz y Gloria Becerra eds.), Feminae, Universidad de Granada, Granada.

Amorós, Celia (1997). Tiempo de feminismo. Col. Feminismos. Madrid: Cátedra.

Beauvoir, Simone (1999). El segundo sexo. Col. Feminismos Vol. I y II, Tercera Edición, Madrid: Cátedra.

Beltrán Pedreira, Elena et al. (2001). Feminismos: Debates Teóricos Contemporáneos, Madrid: Ed. Alianza.

Bleier, Ruth (1984). Science and gender: a critique of Biology and its theories on women, Nueva York: Pergamon Press;

Brighton Women and Science Group (1980). Alice trough the microscopy, Londres: Virago Press.

Bourdieu, Pierre y Jean-Claude Passeron (1970/1979). La reproduction: Éléments d'une théorie du système d'enseignement, Les Éditions de Minuit, coll. Le sens commun. Traducción en español: La reproducción: elementos para una teoría del sistema de enseñanza, Ed. Fontamara, Barcelona. Disponible: https://socioeducacion.files. wordpress.com/2011/05/bourdieu-pierre-la-reproduccion1.pdf

Frías Ruiz, Vicky (Ed.) (2001). Las mujeres ante la ciencia del siglo XXI, Instituto de Investigaciones Feministas y Universidad Complutense de Madrid.

Harding, Sandra (1986/1996). Ciencia y feminismo, Madrid, Ed. Morata. Hubbard, Ruth (2003). « Science, Power, Gender: How DNA Became the Book of Life », Signs, vol. 28, n 3 (Primavera), p. 791-799.

Keller, Evelyn Fox (1983/1984). Seducida por lo vivo, Barcelona, Fontalba.

Keller, Evelyn Fox (1984/1991). Reflexiones sobre Género y Ciencia, Valencia, Ed. Alfons el Magnànim.

Lagarde, Marcela (1997). Género y feminismo. Desarrollo humano y democracia. Madrid: Horas y Horas.

Lamas, Marta (1994). Cuerpo/diferencia sexual y género, en: El Debate feminista, Cuerpo y política, Año 5, vol. 10 (septiembre), México.

Maguire, Patricia (1987). Doing Participatory Research: A Feminist Approach, Massachusetts: University of Massachusetts, p. 79.

Merton, Robert K. (1968). The Matthew Effect in Science, Science, vol. 159 (Enero), p. 56-63.

Molina Petit, Cristina (1994). Dialéctica Feminista de la Ilustración. Barcelona: Anthropos/ Dirección General de la Mujer, CAM.
Ortner, Sherry B. (1979). ¿Es la mujer con respecto al hombre lo que la naturaleza con respecto a la cultura?, en: Antropología y Feminismo (comp.) 0. Harris y K. Young. Ed. Anagrama. Barcelona.

Pérez Sedeño, Eulalia (1999). ¿El poder de una ilusión? Ciencia, Género y Feminismo. En: Feminismo: del pasado al presente. Salamanca: Ediciones Universidad.

Pycior, Helena M. (1993). Reaping the benefits of Collaboration While Avoiding its Pitfalls: Marie Curie's Rise to Scientific Prominence , Social Studies of Science, vol. 23, n 2 (Mayo):301-323.

Rosaldo, Michelle Zimbalist (1974). Mujer, cultura y sociedad: una visión teórica, en: Antropología y Feminismo (Comp.) 0. Harris y K. Young, Barcelona: Anagrama.

Rossiter, Margaret (1995). Women Scientists in America: Before Affirmative Action 1940-1972, Baltimore: Johns Hopkins University Press.

Rossiter, Margaret (1993). The Matthew Matilda Effect en Science, Social Studies of Science, vol. 23, n 2 (Mayo), 325-41.

Rossiter, Margaret (1982). Women Scientists in America: Struggles and Strategies to 1940, Baltimore: John Hopkins University.

Rubin, Gayle (1986). El tráfico de mujeres: notas sobre la économía política del sexo. Trad. de Stella Mastrangelo en: Nueva Antropología. Estudios sobre la mujer: problemas teóricos. Vol. III, No.30, Ludka Gortari (coord.), México: CONACYT/UAM Iztapalapa.

Sayers, Janet (1982). Biological Politics: feminist and anti-feminist perspectives, Nueva York: Tavistock Publications.

Sayre, Anne (1975). Rosalind Franklin and DNA: A Vivid View of What It Is Like to Be a Gifted Woman in an Especially Male Profession, Nueva York: W.W. Norton \& Co.

Schiebinger, Londa (1989/2004). The mind has no sex? Women in the origins of modern science, Cambridge, MA: Harvard University Press. Traducción en español (2004). ¿Tiene sexo la mente? Mujeres en los orígenes de la ciencia moderna. Col. Feminismos, Cátedra, Madrid.

Schiebinger, Londa (1987). The history and Philosophy of Women in Science, Signs, vol. 12, n² 2, p. 305-332.

Watson, James D. (2000). La doble hélice, Alianza Editorial, Madrid. Valcárcel, Amelia (2000). La memoria colectiva y los retos del feminismo, en: Amelia Valcárcel y Rosalia Romero (eds) (2000). Los desafíos del feminismo ante el siglo XXI, col. Hypatia, Instituto Andaluz de la mujer, Sevilla, pags.19-54. Disponible en el periódico Mujeres en red: http://www.mujeresenred.net/spip.php?article241. 


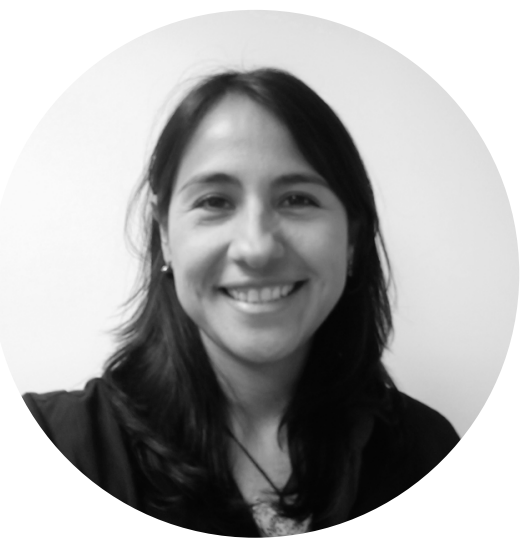

\section{Artemisa \\ Flores Espínola}

Licenciada en sociología por la Universidad Autónoma de Nuevo León y realizó su master en la Universidad Complutense de Madrid (UCM). Obtuvo un doctorado europeo en sociología por la UCM y la Universidad de Paris 8. Actualmente es investigadora en Centro de Investigaciones Sociológicas y Políticas de Paris (CRESPPA) del CNRS. Sus principales líneas de investigación son: género, ciencia y tecnología; metodologías y epistemologías feministas; sociología de las profesiones y del reconocimiento científico; género y educación. Desde el 2011 es responsable (con Danièle Kergoat y Jules Falquet) de la red temática "Sexo, clase y género" de la Asociación Francesa de Sociología.

Correo electrónico:

artemisa.flores-espinola@cnrs.fr 